Review

\title{
Selenium in Bone Health: Roles in Antioxidant Protection and Cell Proliferation
}

\author{
Huawei Zeng *, Jay J. Cao and Gerald F. Combs Jr. \\ Grand Forks Human Nutrition Research Center, Agricultural Research Service, United States \\ Department of Agriculture, Grand Forks, ND 58202, USA; \\ E-Mails: jay.cao@ars.usda.gov (J.J.C.); gerald.combs@ars.usda.gov (G.F.C.) \\ * Author to whom correspondence should be addressed; E-Mail: huawei.zeng@ars.usda.gov; \\ Tel.: +1-7017958465; Fax: +1-7017958220.
}

Received: 28 November 2012; in revised form: 17 December 2012 / Accepted: 3 January 2013 / Published: 10 January 2013

\begin{abstract}
Selenium (Se) is an essential trace element for humans and animals, and several findings suggest that dietary Se intake may be necessary for bone health. Such findings may relate to roles of Se in antioxidant protection, enhanced immune surveillance and modulation of cell proliferation. Elucidation of the mechanisms by which Se supports these cellular processes can lead to a better understanding of the role of this nutrient in normal bone metabolism. This article reviews the current knowledge concerning the molecular functions of Se relevant to bone health.
\end{abstract}

Keywords: antioxidant; bone health; cell proliferation

\section{Introduction}

Selenium (Se) is an essential nutrient, being required at $0.1-0.2 \mathrm{ppm}$ in animal diets, and with a recommended daily allowance of $55 \mu \mathrm{g}$ /day for both men and women [1]. It plays critical roles in a variety of physiological processes as an essential constituent of some 25 selenoenzymes in which it is present as the selenoamino acid, selenocysteine, not found in other proteins [2,3]. The daily needs for Se are met by almost all Americans [4]; however, certain populations in Europe, Africa and Asia have intakes much less than $25 \mu \mathrm{g} /$ day [5].

It has been reported that Se inadequacy can retard growth and change bone metabolism [6,7]. Blood Se concentration has been found to be inversely related to the rate of bone turnover and positively 
correlated with the prevalence of low bone mineral density (BMD) in humans [8]. Low Se intakes have been associated with increased risk to bone disease $[5,7,9,10]$. The results of mechanistic studies have suggested an underlying mechanism, i.e., that of Se playing an essential role in antioxidant defense supporting immune surveillance and cell proliferation and differentiation [3,7,10,11]. In this review, we summarize current knowledge of the effects of Se on bone and the underlying mechanisms.

\section{Relationships of Se and Bone Metabolism}

At least nine selenoproteins are known to be expressed in human fetal osteoblasts [12-14]. Their expression by bone cells would appear to contribute to protection against oxidative stress in the microenvironment of the bone. Excessive intracellular reactive oxygen species (ROS) levels are thought to contribute to the development of osteoporosis by inhibiting osteoblastic differentiation of bone marrow stromal cells (BMSCs) [15-17]. BMSCs cultured in the presence of low Se concentrations $(5-10 \mathrm{nM})$ show reduced expression of glutathione peroxidases (GPXs), thioredoxin reductases (TRRs) and other selenoproteins, as well as the appearance of micronuclei indicative of chromosomal damage [18]. These effects were reversed by treatment with selenite (100 nM) [18]. Genetic data showed that a single nucleotide polymorphism (SNP) at codon 198 of GPX1, is associated with low bone mineral density (BMD), increased bone turnover markers [19] and Kaschin-Beck chondrodystrophy [20]. In addition, three SNPs in the selenoprotein S gene revealed four common haplotypes, showed a significant association to inflammatory signaling (e.g., cytokines), and has been found to be related to osteoarthritis risk [21].

Animal studies have shown Se-deprivation to change bone metabolism [6,7]. Such effects were associated with reductions in the activity of GPX1 and circulating concentrations of pituitary growth hormone, plasma insulin-like growth factor I and calcium, increases in circulating concentrations of parathyroid hormone, 1,25-dihydroxyvitamin $\mathrm{D}_{3}$, and increases in urinary calcium concentration $[6,7]$. That these changes were associated with reduced BMD and bone volume, and with impaired bone microarchitecture indicates they were associated with increased bone resorption [6,7]. Evidence suggests that a role of ROS in promoting bone resorption, as osteoporotic bone tissue, when compared to non-osteoporotic tissue, showed greater levels of lipid peroxides and $\mathrm{H}_{2} \mathrm{O}_{2}$, but lower activities of the antioxidant enzymes superoxide dismutase, GPX3 and glutathione- $S$-transferase [22]. Second-generation of Se-deprived rats also showed reduced growth, and osteopenia [6,23]. Studies with a transgenic mouse model with an osteochondroprogenitor-specific deletion of the selenocysteine tRNA gene (essential for selenoprotein synthesis) [24] showed that the preservation of selenoprotein activity in osteochondroprogenitors is essential to skeletogenesis and the maintenance of cartilage viability. This finding may explain growth retardation, epiphyseal growth plate abnormalities, delayed skeletal ossification and marked chondronecrosis of articular cartilage observed in this model [24].

Studies in humans provide evidence that Se status can be related to bone health. Plasma Se concentration was found to be inversely related to the rate of bone turnover and positively correlated with the prevalence of BMD in healthy euthyroid post-menopausal women [8]. Several years ago, low Se status has been reported in Germany in a group of pediatric patients fed low-Se formula diets; these patients also had low BMD $[25,26]$. Similarly, low BMD and osteoarthropathy have been identified in 
residents of Tibet where Se contents of soils are low [25-27]. A case-control study found Se intake to be inversely associated reduced risk of osteoporotic hip fracture in an elderly population of smokers [10].

\section{Mechanisms of Se in Supporting Bone Health}

There are only a few reported studies of effects of Se on in bone cells [28-30]. However, it is likely that the cellular mechanisms observed in other cell types also occur in bone cells.

\subsection{Se Metabolism}

Foods contain various amounts and chemical forms of Se, most of which is covalently bound to carbon in organic molecules including as selenomethionine (SeMet), selenocysteine (SeCys) and Se-methylselenocysteine (SeMSC) [31,32]. These forms can each be metabolized to selenide $\left(\mathrm{H}_{2} \mathrm{Se}\right)$, which serves as the obligate intermediate in selenoprotein synthesis (Figure 1) [33-37]. SeMet, unlike other forms of Se, can substitute for methionine (Met) in protein synthesis for which reason it is incorporated non-specifically into proteins $[38,39]$. Selenide can also be metabolized by methylation and sugar-derivation to produce a variety of excreted products (Figure 1) [36]. These include selenosugars, which are the major urinary metabolites in humans, and methylselenol $\left(\mathrm{CH}_{3} \mathrm{SeH}\right)$, which is regarded as the major anticarcinogenic Se metabolite [40].

Figure 1. Metabolism of biologically important Se-compounds. Note: This figure is adapted with permission from [38], Copyright (C) 2005 Margaret P. Rayman; and from [39], Copyright (C) 2004 Cancer Research UK.

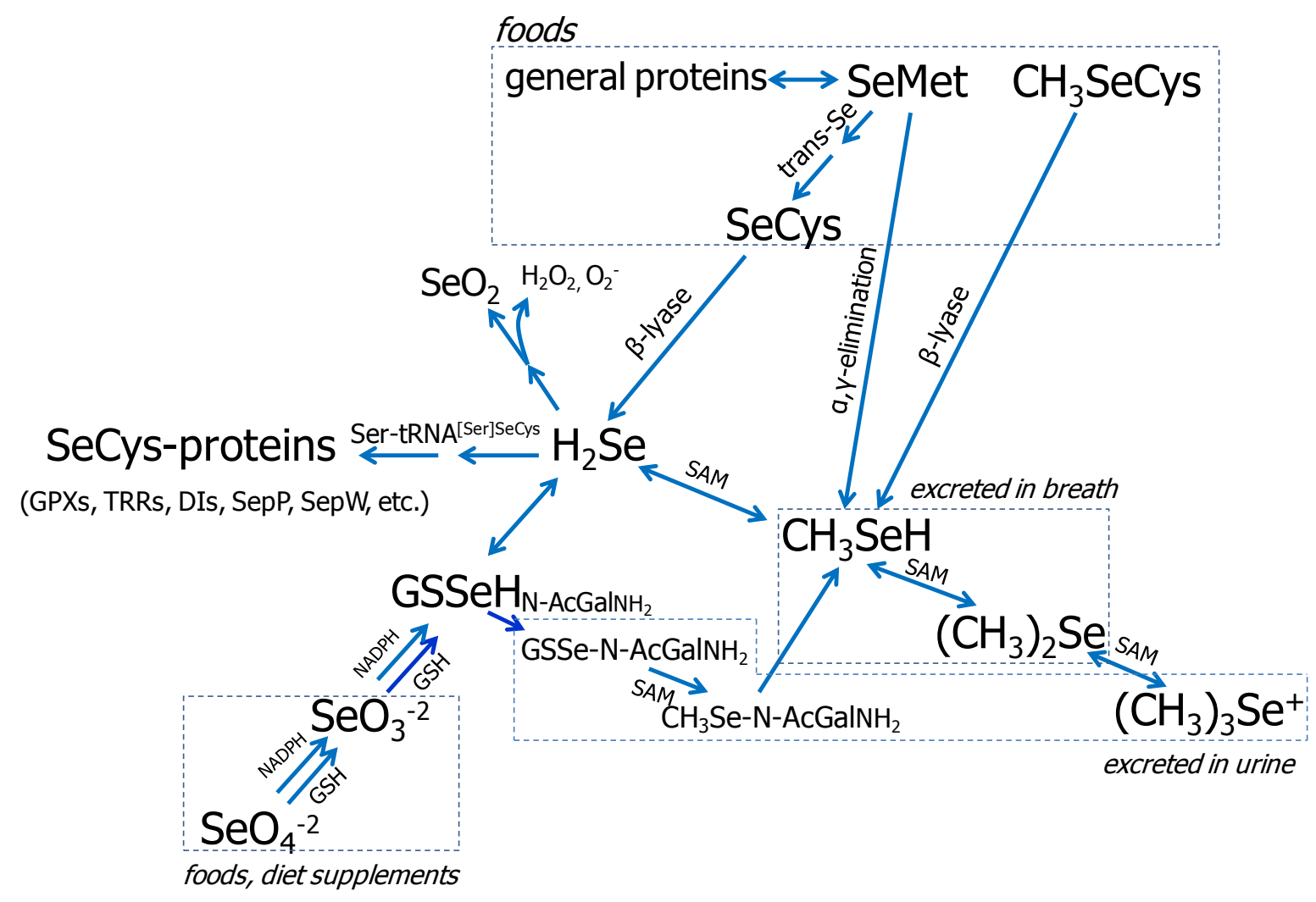


The Se-species that are likely to be present in cells $\left(\mathrm{H}_{2} \mathrm{Se}, \mathrm{CH}_{3} \mathrm{SeH}\right.$ and SeMet) may be biologically active, executing effects by several means: producing ROS by redox cycling of $\mathrm{H}_{2} \mathrm{Se}$ and $\mathrm{CH}_{3} \mathrm{SeH}$; modification of protein-thiols by $\mathrm{CH}_{3} \mathrm{SeH}$; and mimicking Met in protein synthesis by SeMet (Figure 2). It has been suggested that these activities are underlying the cellular effect of high doses of Se $[41,42]$, which includes the regulation of cell cycle and apoptosis. Although many of these biochemical pathways have been characterized in several different cell types, these molecular events may also occur in bone cells.

Figure 2. Molecular mechanisms of Se related to bone health [40-45].

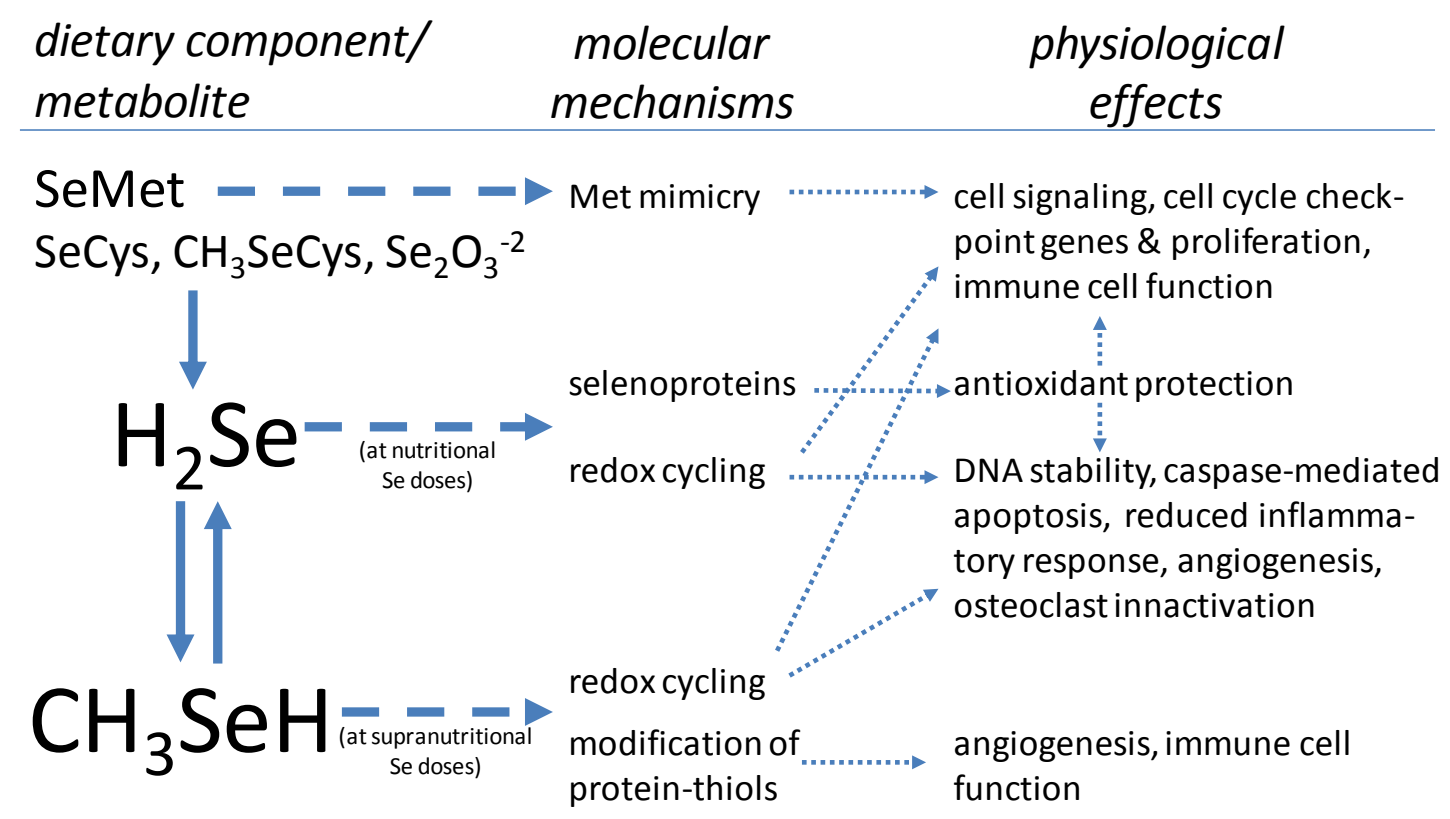

\subsection{The Selenoproteins}

Only 25 selenoprotein genes have been identified in the human genome (24 in the mouse) $[3,46]$. These include the GPXs, TRRs, iodothyronine deiodinases (DIs), selenprotein P (SEPP1) and several less well characterized selenoproteins $[3,46]$. Their synthesis involves the co-translational biosynthesis of SeCys by a unique process in which the UGA codon is recoded to specify SeCys incorporation instead of translational stop [35]. Selenoprotein biosynthesis is dependent on dietary Se intake, genotype and inflammatory tone $[3,35,46,47]$. At limiting levels, this is thought to result in a hierarchal pattern of selenoprotein expression correlating with the relative significance of selenoproteins in cellular function $[3,46]$. The nutritional roles of $\mathrm{Se}$ are thought to be discharged by these selenoproteins most of which appear to exhibit oxidoreductase activities [3,46]. Accordingly, these selenoproteins have been shown to protect cells from ROS, reactive nitrogen species and oxidative damage [47].

\subsection{Se in Protection from Oxidative Stress}

Inadequate $\mathrm{Se}$ intake can result in increased levels of ROS/oxidative stress, particularly in individuals of low status with respect to other antioxidants (e.g., vitamins E and C) [48]. All of the 
enzymatically characterized seleoproteins catalyze not only redox reactions at sulfhydryl groups/disulfides, but also $\mathrm{C}-\mathrm{I}$ bonds catalyzed by deiodinases or $\mathrm{S}-\mathrm{O}$ bonds catalysed by MetSulfoxide Reductase B. [47,48]. An increase in oxidative stress, achieved experimentally either by elevating intracellular ROS or adding exogenous $\mathrm{H}_{2} \mathrm{O}_{2}$ at micromolar concentrations, has been shown to inhibit growth in a wide variety of mammalian cells [49]. Many studies have established that ROS-related oxidative stress induces cell cycle arrest, senescence, apoptosis and/or necrotic cell death $[49,50]$.

ROS have been shown to be important signaling molecules at submicomolar levels, and a biphasic effect has been demonstrated on cellular proliferation with ROS - especially hydrogen peroxide and superoxide - in which low levels (usually submicromolar concentrations) induce growth but higher concentrations (usually $>10-30 \mu \mathrm{M}$ ) induce apoptosis or necrosis [49,50]. For example, cell surface receptors produce ROS upon activation; this includes receptors for epidermal growth factor, platelet-derived growth factor, insulin-like growth factor, vascular endothelial growth factor and various cytokines [47,51,52]. At higher intracellular levels, ROS are damaging to organelles, particularly mitochondria [53], which may result in energy depletion, accumulation of cytotoxic mediators and cell death [53]. Thus, compromised oxidative defense may predispose tissues to damage by environmental stress factors. The maintenance of intracellular redox homeostasis is dependent on a complex web of antioxidant factors including both low molecular weight molecules (e.g., glutathione and thioredoxin) and protein antioxidants (e.g., certain selenoproteins) [53].

\subsection{Se in Cell Proliferation/Differentiation}

Under normal physiological conditions, most cells appear to require Se for normal growth because of their need of selenoproteins. For example, $50 \mathrm{nmol} / \mathrm{L} \mathrm{Se}$, as either selenite or SeMet, is required for the growth of human fibroblasts, lymphocytes and Chinese hamster ovary cells [54-56]. Selenium plays a critical role in cell cycle progression; its omission results in G2 cell cycle arrest [56]. Studies have shown that treatment with either selenite or SeMet can up-regulate the expression of several cell cycle-related genes: $c-M y c$, cyclin $C$, proliferating cell nuclear antigen, cyclin-dependent kinase ( $c d k) 1$, $c d k 2, c d k 4$, cyclin B and cyclin D2 mRNA [56]. In addition, Se increased total cellular phosphorylated proteins [56]. These observations are consistent with the finding that the up-regulation of $c d k 1, c d k 2$, cdk4, cyclin B and cyclin D2 led to the promotion of cell cycle progression, particularly G2/M transition and/or the reduction of apoptosis, in vivo and in vitro [42,57,58]. A few cases have been reported in which certain cells can survive in the absence of Se [59]. This includes most hepatocellular carcinoma cell lines [59]. We found [60] that Se-deprivation did not affect cell cycle progress and apoptosis in human colon Caco-2 cells even though GPX activity was limited to $8 \%$ of that of controls. In that model, Se treatment increased the expression of humoral defense and tumor suppressor-related genes while decreasing the expression of pro-inflammatory genes [60].

Some, but not all, studies have found immune cell proliferation to be sensitive to Se-deprivation $[11,56]$. For example, when derived immune T and B cells (e.g., Jurkat and HL60 cells) were cultured in a Se-deficient, serum-free medium, GPX and TRR activities were low and cells did not survive $[11,56]$. That Se-deprivation increased ROS production in these cells was indicated by the fact that treatment with a lipid soluble radical-scavenging antioxidant (vitamin E) restored survival 
without affecting selenoenzyme expression [11]. Selenium-deficient lymphocytes are less able to proliferate in response to a mitogen, but the response can be improved by supplementing with Se [61].

Adequate Se status has been shown to be essential for an optimum immune response, affecting both the innate and acquired immunity [62]. Inadequate Se intake has been associated with low titers of $\operatorname{IgG}$ and $\operatorname{IgM}$ [63]. Redox tone is known to play a role in modulating the activation of $\mathrm{T}$ cells to effectors [61], and the absence of selenoproteins in T cells led to decreased pools of mature $\mathrm{T}$ cells and defective T cell activation [64].

Only a few Studies have addressed mechanisms underlying the relationship of Se status and bone cell proliferation. However, it is likely that the cellular mechanisms described in other cell types may also occur in bone cells. Indeed, selenoproteins are expressed in osteoblastic cells, and Se supplement restores the antioxidative capacity and prevents cell damage in bone cells (e.g., BMSCs) $[12-14,18]$. For example, TRR has been found to be the responsive gene of $1-\alpha, 25(\mathrm{OH})_{2}$-vitamin $\mathrm{D}_{3}$, the hormone that stimulates bone cell growth and differentiation [65].

Normal bone remodeling appears to depend on the controlled function of ROS. Remodeling is a lifelong process involving the removal of old and damaged bone matrix by osteoclasts and replacement with new bone formed by osteoblasts [66]. Osteoclasts are bone-specific multi-nucleated cells generated from hematopoietic monocyte precursor cells [67]; this differentiation is regulated through both receptor-activation of nuclear factor $\mathrm{\kappa B}$ ligand (RANKL) and macrophage-colony stimulating factor (M-CSF) [66,67]. Bone loss, regardless of cause, reflects increased function of osteoclasts relative to that of osteoblasts $[66,67]$. The latter bone cells generate superoxide by NADPH oxidase [68], and intracellular ROS is known to stimulate the differentiation and formation of mature osteoclasts [69]. That Se and other antioxidants may have a role in this process is suggested by the finding that Se-treatment suppressed RANKL-induced gene expression and phosphor-IкB $\alpha$ activtion [70-72] to reduce RANKL-mediated ROS generation and inhibit the signaling of osteoclast differentiation.

Adequate Se intake appears to play an essential role in osteoclast/osteoblast cell proliferation and differentiation by the regulation of ROS status. Signaling by extracellular signal-regulated kinases ERK1/2 is known to mediate the inhibitory effect of $\mathrm{H}_{2} \mathrm{O}_{2}$ on osteoblastic differentiation in rabbit BMSCs and MC3T3-E1 preosteoblastic cells [15,73].

Recent findings indicate that Se-treatment can protect BMSCs against $\mathrm{H}_{2} \mathrm{O}_{2}$-induced inhibition of osteoblastic differentiation by inhibiting oxidative stress and ERK activation [74]. Treatment with nanomolar amounts of Se, which increased GSH concentraitions and GPX1 expression, also enhanced the expression of type I collagen and alkaline phosphatase, and the deposition of calcium in rat marrow stromal cells (MSCs) [74]. These observations suggest that, at the cellular level, Se was capable of enhancing osteoblastic differentiation of MSCs by reducing basal oxidative stress [74]. In contrast, when selenoprotein expression was decreased due to an inadequate Se intake, ROS levels and phosphorylation status remained elevated and contributed to pathologically exacerbated signaling and enhanced osteoclast activity [13]. Because osteoblasts express several selenoproteins (e.g., GPX, SelP) at high levels it would follow that adequate Se intake is necessary to support this system of osteoblast antioxidative defense that may be relevant for the protection against ROS produced by osteoclasts during bone remodeling [13]. 


\subsection{Effects of High Doses of Se}

Cells treated with high levels of Se typically show alterations in proliferation and differentiation. While these effects have been found to be strongest in cancer cells (and would appear to contribute to the anticarcinogenic activity of Se), they also occur in noncancerous cells [75]. Cells treated with high levels of selenite typically show arrested at the S/G2-M phases with an increase in cdk2 kinase activity and DNA damage-inducible gadd gene [76-80]. In contrast, the metabolite methylselenol $\left(\mathrm{CH}_{3} \mathrm{SeH}\right)$ and its metabolic precursors have been found to induce caspase-mediated apoptosis in those cells [81,82]. Methylselenol has also been shown to activate the caspase cascade and apoptosis $[76,77,83]$. Submicromolar levels of $\mathrm{CH}_{3} \mathrm{SeH}$ have been found to cause cell cycle arrest, leading to increases in cells in the G1 and G2 phases with concomitant reductions of cells in the S-phase [75-77,84]. A metabolic precursor of $\mathrm{CH}_{3} \mathrm{SeH}$, methylselenocyanate (SeMSC), has been shown to exert moderate anti-proliferative effects through G1 cell cycle arrest; whereas, selenite rapidly blocked DNA synthesis and arrested cells in the $\mathrm{S}$ phase [76,77,84]. Cells exposed to methylselenocysteine $\left(\mathrm{CH}_{3} \mathrm{SeCys}\right)$ were arrested at the $\mathrm{G} 1$ phase of the cell cycle as there was a decrease in the cdk2 kinase activity accompanied by a decrease in cyclin E-cdk2 content [78]. In addition, $\mathrm{CH}_{3} \mathrm{SeH}$ exposure of noncancerous NCM460 colon cells inhibited cell growth and led to increases in cells in both the G1 and G2 phases with a concomitant reduction of cells in S-phase and an induction of apoptosis [75]. These responses were associated with reduced phosphorylation of ERK1/2, p38 mitogen-activated protein kinase (MAPK) and cellular myelocytomatosis oncogene (c-Myc) and up-regulation of phosphorylation of sarcoma and focal adhesion kinase survival signals [75]. In general, the doses of Se of these in vitro findings may be higher than that of the in vivo findings (human studies) [75,85-87]. However, the underlying biochemical mechanisms are likely to be the same.

High-dose Se treatment appears to enhance the capacity of lymphocytes to respond to mitogen or alloantigen stimulation, to proliferate, and to differentiate into cytotoxic effector cells. Humans receiving a supranutritional Se dose $(200 \mu \mathrm{g}$ /day) showed increased potential for cytotoxic $\mathrm{T}$ lymphocyte (CTL)-driven tumor lysis, mitogen-induced lymphocyte proliferation, and mixed lymphocyte reaction proliferation compared with a placebo group [85]. In both animals and humans, $\mathrm{CD}^{+} \mathrm{T}$ cells play a crucial in initiating immune responses, and antigen-specific $\mathrm{CD}^{+} \mathrm{T}$ cell proliferation and activation have been found to be increased in response to treatment with supranutritional amounts of Se [86]. Also, Se appears to abrogate the age-related deficiency of lymphocytes to respond to stimulation by proliferation and differentiation into cytotoxic effector cells [85]. However, the molecular mechanisms mediating these effects remain largely unexplored.

Because bone contains appreciable amounts of Se [87], it likely that Se plays a role in bone health. The hematopoietic system has been implicated as a primary target of Se at high doses [88], and osteoclasts are derived from hematopoietic progenitor cells of the monocyte-macrophage lineage [43]. Accordingly, selenite-treatment of osteoclast-like cells (e.g., RAW 264.7 cells) induced apoptosis as revealed by morphological changes, internucleosomal DNA fragmentation, activation of caspase-3, and generated the superoxide anion [28]. These findings indicate that selenite can induce apoptosis through the mitochondrial pathway in mature osteoclasts. 
Osteoclasts are known to be activated by inflammatory cytokines released at low levels by osteoblasts [30]. That Se can alleviate the NF-kB dependent regulation of the inflammatory response suggests that it may have a role in mediating the osteoblast-ostoclast crosstalk $[44,45]$. Recent data have shown that supplementation of osteoblasts with MSeA reduced the activation of NF- $\mathrm{B}$, leading to decrease in interleukin (IL)-6, monocyte chemoattractant protein-1 (MCP-1), cyclooxygenase-2 (COX-2) and inducible nitric oxide synthase (iNOS) [30]. Thus, it is likely that Se, at least at high doses, can prevent bone resorption through the inactivation of osteoclasts. Consistent with this observation, a recent study demonstrated that Se status was inversely related to bone turnover and positively correlated with BMD in healthy euthyroid postmenopausal women independent of thyroid status [8]. However, the other study indicated that elevated Se intake negatively affected bone mass measurements in postmenopausal women over the age of 51 but only if calcium intake was less than $800 \mathrm{mg} /$ day [89]. Therefore, more future human studies are needed to determine the beneficial effect of Se on bone health.

\section{Conclusions}

Selenium is an essential nutrient that appears to play a role in bone health. That role is likely to involve the functions of selenoproteins. Many, if not all, selenoproteins are antioxidant enzymes that participate in maintaining cell redox balance, which is important in the regulation of inflammation and bone cell proliferation/differentiation. Selenium may play additional cellular roles, particularly at supranutritional doses, i.e., doses greater than those required for maximal selenoprotein expression. These include the induction of cell cycle arrest, apoptosis, immune function, and the prevention of the bone resorption through the inactivation of osteoclasts (Figure 2). These cellular activities of Se at both nutritional and supranutritional doses may partially account for the potential protection against rheumatoid arthritis, osteoarthritis, osteoporosis and ROS produced by osteoclasts during bone remodeling [13,90-92].

\section{Conflict of Interest}

The authors declare no conflict of interest.

\section{Reference}

1. Whanger, P.D. Selenium and its relationship to cancer: An update. Br. J. Nutr. 2004, 91, 11-28.

2. Rayman, M.P. Selenoproteins and human health: Insights from epidemiological data. Biochim. Biophys. Acta 2009, 1790, 1533-1540.

3. Davis, C.D.; Tsuji, P.A.; Milner, J.A. Selenoproteins and cancer prevention. Annu. Rev. Nutr. 2012, 32, 73-95.

4. Institute of Medicine, Food and Nutrition Board. Dietary Reference Intakes; National Academy Press: Washington, DC, USA, 2000.

5. Johnson, C.C.; Fordyce, F.M.; Rayman, M.P. Symposium on 'Geographical and geological influences on nutrition': Factors controlling the distribution of selenium in the environment and their impact on health and nutrition. Proc. Nutr. Soc. 2010, 69, 119-132. 
6. Moreno-Reyes, R.; Egrise, D.; Neve, J.; Pasteels, J.L.; Schoutens, A. Selenium deficiency-induced growth retardation is associated with an impaired bone metabolism and osteopenia. J. Bone Miner. Res. 2001, 16, 1556-1563.

7. Cao, J.J.; Gregoire, B.R.; Zeng, H. Selenium deficiency decreases antioxidative capacity and is detrimental to bone microarchitecture in mice. J. Nutr. 2012, 142, 1526-1531.

8. Hoeg, A.; Gogakos, A.; Murphy, E.; Mueller, S.; Köhrle, J.; Reid, D.M.; Glüer, C.C.; Felsenberg, D.; Roux, C.; Eastell, R.; et al. Bone turnover and bone mineral density are independently related to selenium status in healthy euthyroid postmenopausal women. J. Clin. Endocrinol. Metab. 2012, 97, 4061-4070.

9. Manolagas, S.C. From estrogen-centric to aging and oxidative stress: A revised perspective of the pathogenesis of osteoporosis. Endocr. Rev. 2010, 31, 266-300.

10. Zhang, J.; Munger, R.G.; West, N.A.; Cutler, D.R.; Wengreen, H.J.; Corcoran, C.D. Antioxidant intake and risk of osteoporotic hip fracture in Utah: An effect modified by smoking status. Am. J. Epidemiol. 2006, 163, 9-17.

11. Saito, Y.; Yoshida, Y.; Akazawa, T.; Takahashi, K.; Niki, E. Cell death caused by selenium deficiency and protective effect of antioxidants. J. Biol. Chem. 2003, 278, 39428-39434.

12. Köhrle, J.; Jakob, F.; Contempré, B.; Dumont, J.E. Selenium, the thyroid, and the endocrine system. Endocr. Rev. 2005, 26, 944-984.

13. Dreher, I.; Schütze, N.; Baur, A.; Hesse, K.; Schneider, D.; Köhrle, J.; Jakob, F. Selenoproteins are expressed in fetal human osteoblast-like cells. Biochem. Biophys. Res. Commun. 1998, 245 , 101-107.

14. Jakob, F.; Becker, K.; Paar, E.; Ebert-Duemig, R.; Schütze, N. Expression and regulation of thioredoxin reductases and other selenoproteins in bone. Methods Enzymol. 2002, 347, 168-179.

15. Xu, Z.S.; Wang, X.Y.; Xiao, D.M.; Hu, L.F.; Lu, M.; Wu, Z.Y.; Bian, J.S. Hydrogen sulfide protects MC3T3-E1 osteoblastic cells against $\mathrm{H}_{2} \mathrm{O}_{2}$-induced oxidative damage-implications for the treatment of osteoporosis. Free Radic. Biol. Med. 2011, 50, 1314-1323.

16. Mody, N.; Parhami, F.; Sarafian, T.A.; Demer, L.L. Oxidative stress modulates osteoblastic differentiation of vascular and bone cells. Free Radic. Biol. Med. 2001, 31, 509-519.

17. Almeida, M.; Ambrogini, E.; Han, L.; Manolagas, S.C.; Jilka, R.L. Increased lipid oxidation causes oxidative stress, increased peroxisome proliferator-activated receptor-gamma expression, and diminished pro-osteogenic Wnt signaling in the skeleton. J. Biol. Chem. 2009, 284, 27438-27448.

18. Ebert, R.; Ulmer, M.; Zeck, S.; Meissner-Weigl, J.; Schneider, D.; Stopper, H.; Schupp, N.; Kassem, M.; Jakob, F. Selenium supplementation restores the antioxidative capacity and prevents cell damage in bone marrow stromal cells in vitro. Stem Cells 2006, 24, 1226-1235.

19. Mlakar, S.J.; Osredkar, J.; Prezelj, J.; Marc, J. The antioxidant enzyme GPX1 gene polymorphisms are associated with low BMD and increased bone turnover markers. Dis. Markers 2010, 29, 71-80.

20. Sun, J.; Sun, Q.; Lu, S. From selenoprotein to endochondral ossification: A novel mechanism with microRNAs potential in bone related diseases? Med. Hypotheses 2011, 77, 807-811. 
21. Bos, S.D.; Kloppenburg, M.; Suchiman, E.; van Beelen, E.; Slagboom, P.E.; Meulenbelt, I. The role of plasma cytokine levels, CRP and Selenoprotein S gene variation in OA. Osteoarthritis Cartilage 2009, 17, 621-626.

22. Muthusami, S.; Ramachandran, I.; Muthusamy, B.; Vasudevan, G.; Prabhu, V.; Subramaniam, V.; Jagadeesan, A.; Narasimhan, S. Ovariectomy induces oxidative stress and impairs bone antioxidant system in adult rats. Clin. Chim. Acta 2005, 360, 81-86.

23. Ren, F.L.; Guo, X.; Zhang, R.J.; Wang, Sh.J.; Zuo, H.; Zhang, Z.T.; Geng, D.; Yu, Y.; Su, M. Effects of selenium and iodine deficiency on bone, cartilage growth plate and chondrocyte differentiation in two generations of rats. Osteoarthritis Cartilage 2007, 15, 1171-1177.

24. Downey, C.M.; Horton, C.R.; Carlson, B.A.; Parsons, T.E.; Hatfield, D.L.; Hallgrímsson, B.; Jirik, F.R. Osteo-chondroprogenitor-specific deletion of the selenocysteine tRNA gene, Trsp, leads to chondronecrosis and abnormal skeletal development: A putative model for Kashin-Beck disease. PLoS Genet. 2009, 5, e1000616.

25. Allen, J.R.; Humphries, I.R.; Waters, D.L.; Roberts, D.C.; Lipson, A.H.; Howman-Giles, R.G.; Gaskin, K.J. Decreased bone mineral density in children with phenylketonuria. Am. J. Clin. Nutr. 1994, 59, 419-422.

26. Zeman, J.; Bayer, M.; Stepán, J. Bone mineral density in patients with phenylketonuria. Acta Paediatr. 1999, 88, 1348-1351.

27. $\mathrm{Wu}, \mathrm{J} . ; \mathrm{Xu}, \mathrm{G} . \mathrm{L}$. Plasma selenium content, platelet glutathione peroxidase and superoxide dismutase activity of residents in Kashin-Beck disease affected area in China. J. Trace Elem. Electrolytes Health Dis. 1987, 1, 39-43.

28. Chung, Y.W.; Kim, T.S.; Lee, S.Y.; Lee, S.H.; Choi, Y.; Kim, N.; Min, B.M.; Jeong, D.W.; Kim, I.Y. Selenite-induced apoptosis of osteoclasts mediated by the mitochondrial pathway. Toxicol. Lett. 2006, 160, 143-150.

29. Hiraoka, K.; Komiya, S.; Hamada, T.; Zenmyo, M.; Inoue, A. Osteosarcoma cell apoptosis induced by selenium. J. Orthop. Res. 2001, 19, 809-814.

30. Chen, Y.C.; Sosnoski, D.M.; Gandhi, U.H.; Novinger, L.J.; Prabhu, K.S.; Mastro, A.M. Selenium modifies the osteoblast inflammatory stress response to bone metastatic breast cancer. Carcinogenesis 2009, 30, 1941-1948 .

31. Ip, C.; Birringer, M.; Block, E.; Kotrebai, M.; Tyson, J.F.; Uden, P.C.; Lisk, D.J. Chemical speciation influences comparative activity of selenium-enriched garlic and yeast in mammary cancer prevention. J. Agric. Food Chem. 2000, 48, 2062-2070.

32. Schrauzer, G.N. Nutritional selenium supplements: Product types, quality, and safety. J. Am. Coll. Nutr. 2001, 20, 1-4.

33. Ganther, H.E. Selenium metabolism, selenoproteins and mechanisms of cancer prevention: Complexities with thioredoxin reductase. Carcinogenesis 1999, 20, 1657-1666.

34. Ip, C.; Ganther, H. Efficacy of trimethylselenonium versus selenite in cancer chemoprevention and its modulation by arsenite. Carcinogenesis 1988, 9, 1481-1484.

35. Gladyshev, V.N.; Hatfield, D.L. Selenocysteine-containing proteins in mammals. J. Biomed. Sci. 1999, 6, 151-160.

36. Sunde, R.A. Selenium. In Present Knowledge in Nutrition, 9th ed.; Bowman, B.A., Russell, R.M., Eds.; ILSI Press Inc: Washington, DC, USA, 2006; pp. 480-497. 
37. Kobayashi, Y.; Ogra, Y.; Ishiwata, K.; Takayama, H.; Aimi, N.; Suzuki, K.T. Selenosugars are key and urinary metabolites for selenium excretion within the required to low-toxic range. Proc. Natl. Acad. Sci. USA 2002, 99, 15932-15936.

38. Rayman, M.P. Selenium in cancer prevention: A review of the evidence and mechanism of action. Proc. Nutr. Soc. 2005, 64, 527-542.

39. Combs, G.F., Jr. Status of selenium in prostate cancer prevention. Br. J. Cancer 2004, 91, 195-199.

40. Ip, C.; Ganther, H.E. Activity of methylated forms of selenium in cancer prevention. Cancer Res. 1990, 50, 1206-1211.

41. Zeng, H. Selenium as an essential micronutrient: Roles in cell cycle and apoptosis. Molecules 2009, 14, 1263-1278.

42. Kaushal, N.; Bansal, M.P. Dietary selenium variation-induced oxidative stress modulates CDC2/cyclin B1 expression and apoptosis of germ cells in mice testis. J. Nutr. Biochem. 2007, 18, 553-564.

43. Udagawa, N.; Takahashi, N.; Akatsu, T.; Tanaka, H.; Sasaki, T.; Nishihara, T.; Koga, T.; Martin, T.J.; Suda, T. Origin of osteoclasts: Mature monocytes and macrophages are capable of differentiating into osteoclasts under a suitable microenvironment prepared by bone marrow-derived stromal cells. Proc. Natl. Acad. Sci. USA 1990, 87, 7260-7264.

44. Christensen, M.J.; Nartey, E.T.; Hada, A.L.; Legg, R.L.; Barzee, B.R. High selenium reduces NF-kappaB-regulated gene expression in uninduced human prostate cancer cells. Nutr. Cancer 2007, 58, 197-204.

45. Duntas, L.H. Selenium and inflammation: Underlying anti-inflammatory mechanisms. Horm. Metab. Res. 2009, 41, 443-437.

46. Méplan, C.; Hesketh, J. The influence of selenium and selenoprotein gene variants on colorectal cancer risk. Mutagenesis 2012, 27, 177-186.

47. Hawkes, W.C.; Alkan, Z. Regulation of redox signaling by selenoproteins. Biol. Trace Elem. Res. 2010, 134, 235-251.

48. Steinbrenner, H.; Sies, H. Protection against reactive oxygen species by selenoproteins. Biochim. Biophys. Acta 2009, 1790, 1478-1485.

49. Day, R.M.; Suzuki, Y.J. Cell proliferation, reactive oxygen and cellular glutathione. Dose Response 2006, 3, 425-442.

50. Stone, J.R.; Yang, S. Hydrogen peroxide: A signaling messenger. Antioxid. Redox Signal. 2006, 8, 243-270.

51. Vardatsikos, G.; Sahu, A.; Srivastava, A.K. The insulin-like growth factor family: Molecular mechanisms, redox regulation, and clinical implications. Antioxid. Redox Signal. 2009, 11, 1165-1190.

52. Purushothaman, D.; Sarin, A. Cytokine-dependent regulation of NADPH oxidase activity and the consequences for activated T cell homeostasis. J. Exp. Med. 2009, 206, 1515-1523.

53. Lee, J.; Giordano, S.; Zhang, J. Autophagy, mitochondria and oxidative stress: Cross-talk and redox signalling. Biochem. J. 2012, 441, 523-540.

54. McKeehan, W.L.; Hamilton, W.G.; Ham, R.G. Selenium is an essential trace nutrient for growth of WI-38 diploid human fibroblasts. Proc. Natl. Acad. Sci. USA 1976, 73, 2023-2027. 
55. Guilbert, L.J.; Iscove, N.N. Partial replacement of serum by selenite, transferrin, albumin and lecithin in haemopoietic cell cultures. Nature 1976, 263, 594-595.

56. Zeng, H. Selenite and selenomethionine promote HL-60 cell cycle progression. J. Nutr. 2002, 132, 674-679.

57. Hu, B.; Mitra, J.; van den, H.S.; Enders, G.H. S and G2 phase roles for Cdk2 revealed by inducible expression of a dominant-negative mutant in human cells. Mol. Cell. Biol. 2001, 21, 2755-2766.

58. Gille, H.; Downward, J. Multiple ras effector pathways contribute to G(1) cell cycle progression. J. Biol. Chem. 1999, 274, 22033-22040.

59. Irmak, M.B.; Ince, G.; Ozturk, M.; Cetin-Atalay, R. Acquired tolerance of hepatocellular carcinoma cells to selenium deficiency: A selective survival mechanism? Cancer Res. 2003, 63, 6707-6715.

60. Zeng, H.; Botnen, J.H. Selenium is critical for cancer-signaling gene expression but not cell proliferation in human colon Caco-2 cells. Biofactors 2007, 31, 155-164.

61. Williams, M.S.; Henkart, P.A. Role of reactive oxygen intermediates in TCR-induced death of T cell blasts and hybridomas. J. Immunol. 1996, 157, 2395-2402.

62. Bhaskaram, P. Micronutrient malnutrition, infection, and immunity: An overview. Nutr. Rev. 2002, 60, S40-S45.

63. Arthur, J.R.; McKenzie, R.C.; Beckett G.J. Selenium in the immune system. J. Nutr. 2003, 133, 1457S-1459S.

64. Shrimali, R.K.; Irons, R.D.; Carlson, B.A.; Sano, Y.; Gladyshev, V.N.; Park, J.M.; Hatfield, D.L. Selenoproteins mediate $\mathrm{T}$ cell immunity through an antioxidant mechanism. J. Biol. Chem. 2008, 283, 20181-20185.

65. Schütze, N.; Bachthaler, M.; Lechner, A.; Köhrle, J.; Jakob, F. Identification by differential display PCR of the selenoprotein thioredoxin reductase as a 1 alpha,25(OH)2-vitamin D3-responsive gene in human osteoblasts - Regulation by selenite. Biofactors 1998, 7, 299-310.

66. Boyce, B.F.; Xing, L. The RANKL/RANK/OPG pathway. Curr. Osteoporos. Rep. 2007, 5, 98-104.

67. Teitelbaum, S.L.; Ross, F.P. Genetic regulation of osteoclast development and function. Nat. Rev. Genet. 2003, 4, 638-649.

68. Yang, S.; Zhang, Y.; Ries, W.; Key, L. Expression of Nox4 in osteoclasts. J. Cell Biochem. 2004, 92, 238-248.

69. Steinbeck, M.J.; Kim, J.K.; Trudeau, M.J.; Hauschka, P.V.; Karnovsky, M.J. Involvement of hydrogen peroxide in the differentiation of clonal HD-11EM cells into osteoclast-like cells. J. Cell Physiol. 1998, 176, 574-587.

70. Moon, H.J.; Ko, W.K.; Han, S.W.; Kim, D.S.; Hwang, Y.S.; Park, H.K.; Kwon, I.K. Antioxidants, like coenzyme Q10, selenite, and curcumin, inhibited osteoclast differentiation by suppressing reactive oxygen species generation. Biochem. Biophys. Res. Commun. 2012, 418, 247-253.

71. Lean, J.M.; Jagger, C.J.; Kirstein, B.; Fuller, K.; Chambers, T.J. Hydrogen peroxide is essential for estrogen-deficiency bone loss and osteoclast formation. Endocrinology 2005, 146, 728-735.

72. Sheweita, S.A.; Khoshhal, K.I. Calcium metabolism and oxidative stress in bone fractures: Role of antioxidants. Curr. Drug Metab. 2007, 8, 519-525. 
73. Bai, X.C.; Lu, D.; Bai, J.; Zheng, H.; Ke, Z.Y.; Li, X.M.; Luo, S.Q. Oxidative stress inhibits osteoblastic differentiation of bone cells by ERK and NF-kappaB. Biochem. Biophys. Res. Commun. 2004, 314, 197-207.

74. Liu, H.; Bian, W.; Liu, S.; Huang, K. Selenium protects bone marrow stromal cells against hydrogen peroxide-induced inhibition of osteoblastic differentiation by suppressing oxidative stress and ERK signaling pathway. Biol. Trace Elem. Res. 2012, 150, 441-450.

75. Zeng, H.; Briske-Anderson, M.; Wu, M.; Moyer, M.P. Methylselenol, a selenium metabolite, plays common and different role in cancerous colon HCT116 cell and noncancerous NCM460 colon cell proliferation. Nutr. Cancer 2012, 64, 128-135.

76. Wang, Z.; Jiang, C.; Lu, J. Induction of caspase-mediated apoptosis and cell-cycle G1 arrest by selenium metabolite methylselenol. Mol. Carcinog. 2002, 34, 113-120.

77. Zeng, H.; Briske-Anderson, M.; Idso, J.P.; Hunt, C.D. The selenium metabolite methylselenol inhibits the migration and invasion potential of HT1080 tumor cells. J. Nutr. 2006, 136, 1528-1532.

78. Sinha, R.; Said, T.K.; Medina, D. Organic and inorganic selenium compounds inhibit mouse mammary cell growth in vitro by different cellular pathways. Cancer Lett. 1996, 107, 277-284.

79. Kaeck, M.; Lu, J.; Strange, R.; Ip, C.; Ganther, H.E.; Thompson, H.J. Differential induction of growth arrest inducible genes by selenium compounds. Biochem. Pharmacol. 1997, 53, 921-926.

80. Zeng, H.; Davis, C.D. Down-regulation of proliferating cell nuclear antigen gene expression occurs during cell cycle arrest induced by human fecal water in colonic HT-29 cells. J. Nutr. 2003, 133, 2682-2687.

81. Jiang, C.; Wang, Z.; Ganther, H.; Lu, J. Distinct effects of methylseleninic acid versus selenite on apoptosis, cell cycle, and protein kinase pathways in DU145 human prostate cancer cells. Mol. Cancer Ther. 2002, 1, 1059-1066.

82. Kim, A.; Oh, J.H.; Park, J.M.; Chung, A.S. Methylselenol generated from selenomethionine by methioninase downregulates integrin expression and induces caspase-mediated apoptosis of B16F10 melanoma cells. J. Cell Physiol. 2007, 212, 386-400.

83. Miki, K.; Xu, M.; Gupta, A.; Ba, Y.; Tan, Y.; Al-Refaie, W.; Bouvet, M.; Makuuchi, M.; Moossa, A.R.; Hoffman, R.M. Methioninase cancer gene therapy with selenomethionine as suicide prodrug substrate. Cancer Res. 2001, 61, 6805-6810.

84. Zeng, H.; Wu, M.; Botnen, J.H. Methylselenol, a selenium metabolite, induces cell cycle arrest in G1 phase and apoptosis via the extracellular-regulated kinase $1 / 2$ pathway and other cancer signaling genes. J. Nutr. 2009, 139, 1613-1618.

85. Kiremidjian-Schumacher, L.; Roy, M. Effect of selenium on the immunocompetence of patients with head and neck cancer and on adoptive immunotherapy of early and established lesions. Biofactors 2001, 14, 161-168.

86. Hoffmann, F.W.; Hashimoto, A.C.; Shafer, L.A.; Dow, S.; Berry, M.J.; Hoffmann, P.R. Dietary selenium modulates activation and differentiation of CD4+ T cells in mice through a mechanism involving cellular free thiols. J. Nutr. 2010, 140, 1155-1161.

87. Zachara, B.A.; Pawluk, H.; Bloch-Boguslawska, E.; Sliwka, K.M.; Korenkiewicz, J.; Skok, Z.; Ryć, K. Tissue level, distribution, and total body selenium content in healthy and diseased humans in Poland. Arch. Environ. Health 2001, 56, 461-466. 
88. Raisbeck, M.F. Selenosis. Vet. Clin. North Am. Food Anim. Pract. 2000, 16, 465-480.

89. Pedrera-Zamorano, J.D.; Calderon-García, J.F.; Roncero-Martin, R.; Mañas-Nuñez, P.; Moran, J.M.; Lavado-Garcia, J.M. The protective effect of calcium on bone mass in postmenopausal women with high selenium intake. J. Nutr. Health Aging 2012, 16, 743-748.

90. Yazar, M.; Sarban, S.; Kocyigit, A.; Isikan, U.E. Synovial fluid and plasma selenium, copper, zinc, and iron concentrations in patients with rheumatoid arthritis and osteoarthritis. Biol. Trace Elem. Res. 2005, 106, 123-132.

91. Canter, P.H.; Wider, B.; Ernst, E. The antioxidant vitamins A, C, E and selenium in the treatment of arthritis: A systematic review of randomized clinical trials. Rheumatology 2007, 46, 1223-1233.

92. Turan, B.; Can, B.; Delilbasi, E. Selenium combined with vitamin E and vitamin C restores structural alterations of bones in heparin-induced osteoporosis. Clin. Rheumatol. 2003, 22, 432-436.

(C) 2013 by the authors; licensee MDPI, Basel, Switzerland. This article is an open access article distributed under the terms and conditions of the Creative Commons Attribution license (http://creativecommons.org/licenses/by/3.0/). 